\title{
Tocilizumab, Adipokines and Severe Complications of COVID-19
}

\author{
Antonella Fioravanti ${ }^{1} \cdot$ Brunetta Porcelli $^{2} \cdot$ Lucia Terzuoli $^{2} \cdot$ Maria Romana Bacarelli $^{1} \cdot$ Sara Tenti ${ }^{2}$ Sara Cheleschi ${ }^{1}$ (I)
}

Published online: 13 July 2020

(c) Springer Nature Switzerland AG 2020

To the Editor: A recent article published by Zhang et al. [1] discussed the possible mechanism of action of tocilizumab in the treatment of patients with severe COVID-19 and stimulated some considerations on the basis of our previous experience.

Obesity is considered as a major risk factor for serious COVID-19-related complications, such as severe acute respiratory syndrome coronavirus 2 (SARS-CoV-2) [2].

The link between obesity and acute lung injury during infection can be partially explained by the activation of the renin-angiotensin system. It has been supposed that the virus uses an angiotensin-converting enzyme 2 (ACE2)-dependent mechanism of cellular entry; this receptor is also expressed in adipocytes, including ectopic adipocytes within the alveolar interstitial [3].

However, we can postulate that obesity may predispose to the development and progression of the COVID-19 disease through several mechanisms. Growing evidence demonstrated that adipose tissue is an active endocrine organ and secretes many substances known as "adipocytokines" such as adiponectin, leptin, resistin, visfatin, chemerin, tumor necrosis factor (TNF)- $\alpha$, interleukin (IL)-6, factors of the complement system, growth factors, and adhesion molecules, involved in the regulation of several processes including inflammation and immunity. Then, an abnormal secretion of adipocytokines from fat tissue can contribute to development of the condition described as "cytokine storm" which characterized the severe form of SARS-CoV-2.

This comment refers to the article available online at https://doi. org/10.1007/s40261-020-00917-3.

Sara Cheleschi

saracheleschi@hotmail.com

1 Rheumatology Unit, Department of Medicine, Surgery and Neuroscience, Azienda Ospedaliera Universitaria Senese, Policlinico Le Scotte, Viale Bracci 1, 53100 Siena, Italy

2 Section of Biochemistry, Department of Medical Biotechnologies, University of Siena, 53100 Siena, Italy
Tocilizumab, a humanized monoclonal antibody that acts as an IL-6 receptor antagonist, has shown remarkable efficacy and safety in the treatment of established rheumatoid arthritis (RA), systemic juvenile idiopathic arthritis, giant cell arteritis, and cytokine release syndrome. Since March 3, 2020 the National Health Commission of China has formally included intravenous (IV) tocilizumab in the treatment program of COVID-19 for its capacity to reduce or reverse the cytokine storm [4]. Also, Italian guidelines support the use of IV tocilizumab in patients with severe or critical complication of COVID-19 [5]. Preliminary results showed clinical efficacy of the drug with reduction of temperature, improvement of respiratory function, decrease of C-reactive protein and mortality associated with a favorable safety profile $[6,7]$.

Among the possible mechanisms of action of tocilizumab in the COVID-19 infection, it seems of relevance to consider the effect on adipokines and on pro-thrombotic factors demonstrated in patients with RA [8,9]. Indeed, this drug is able to increase serum levels of adiponectin and to reduce circulating leptin, chemerin, plasminogen activator inhibitor-1 (PAI-1), and fibrinogen [8-10].

Adiponectin is an adipokine with insulin-sensitizing and anti-atherogenic properties; hypoadiponectinemia has been shown to be associated with obesity, diabetes, metabolic inflammatory syndrome and inflammation [11, 12], also, low serum levels of adiponectin were reported as predictor of mortality in critically ill patients in intensive care units [13]. Leptin has pro-inflammatory properties stimulating the production of TNF- $\alpha$, IL- 6 , and IL-12 and potential atherogenic effects [14].

Chemerin is a novel adipokine involved in inflammation (stimulates chemotaxis, macrophages, and dendritic cells, induces the release of IL-6), in coagulation and fibrinolysis; furthermore, elevated circulating chemerin levels correlate with endothelial dysfunction [14].

With these observations, we suggest that tocilizumab could be effective in the treatment of severe complications of patients with COVID-19, with a particular relevance in obesity, for its effect on adipocytokines and, in turn, in reducing 
the cytokine storm. Furthermore, the anti-thrombotic/ fibrinolytic action of the drug appears relevant considering the high risk of hypercoagulability and venous or arterial thrombosis in critical phase of COVID-19 infection [15].

Author Contributions AF and SC conceptualization; AF and SC writing - Original Draft Preparation; BP, LT, MRB, and ST writing, review and editing.

\section{Compliance with Ethical Standards}

Funding This work has not been supported by any fund.

Conflict of interest The authors declare no competing interests.

\section{References}

1. Zhang S, Li L, Shen A, Chen Y, Qi Z. Rational Use of tocilizumab in the treatment of novel coronavirus pneumonia. Clin Drug Investig. 2020;40:511-8. https://doi.org/10.1007/s40261-020-00917-3.

2. Ryan DH, Ravussin E, Heymsfield S. COVID 19 and the patient with obesity - the editor speak out. Obesity (Silver Spring). 2020;28:847. https://doi.org/10.1002/oby.2280.

3. Malavazos AE, Corsi Romanelli MM, Bandera F, Iacobellis G. Targeting the Adipose Tissue in COVID-19. Obesity (Silver Spring). 2020. https://doi.org/10.1002/oby.22844 (Epub ahead of print).

4. National Health Commission \& State Administration of Traditional Chinese Medicine. Diagnosis and Treatment Protocol for Novel Coronavirus Pneumonia. Trial Version 7. Released on March 3, 2020. http://en.nhc.gov.cn/2020-03/29/c_78469.htm. Accessed 13 Jul 2020.

5. SIMIT Società Italiana di Malattie Infettive e Tropicali. Linee guida sulla gestione terapeutica e di supporto per pazienti con infezione da coronavirus COVID-19. Edizione 2.0, 12 marzo 2020

6. Fu B, Xu X, Wei H. Why tocilizumab could be an effective treatment for severe COVID-19? J Transl Med. 2020;18:164. https:// doi.org/10.1186/s12967-020-02339-3.
7. Ortiz-Martínez Y. Tocilizumab: a new opportunity in the possible therapeutic arsenal against COVID-19. Travel Med Infect Dis. 2020. https://doi.org/10.1016/j.tmaid.2020.101678.

8. Makrilakis K, Fragiadaki K, Smith J, Sfikakis P, Kitas G. Interrelated reduction of chemerin and plasminogen activator inhibitor-1 serum levels in rheumatoid arthritis after interleukin-6 receptor blockade. Clin Rheumatol. 2015;34:419-27. https://doi. org/10.3899/jrheum.141115.

9. Fioravanti A, Tenti S, Bacarelli MR, Damiani A, Li Gobbi F, Bandinelli F, et al. Tocilizumab modulates serum levels of adiponectin and chemerin in patients with rheumatoid arthritis: potential cardiovascular protective role of IL-6 inhibition. Clin Exp Rheumatol. 2019;37:293-300.

10. Tournadre A, Pereira B, Dutheil F, Giraud C, Courteix D, Sapin V, et al. Changes in body composition and metabolic profile during interleukin 6 inhibition in rheumatoid arthritis. J Cachexia Sarcopenia Muscle. 2017;8:639-46. https://doi.org/10.1002/jcsm.12189.

11. Salvator H, Grassin-Delyle S, Naline E, Brollo M, Fournier C, Couderc LJ, et al. Contrasting effects of adipokines on the cytokine production by primary human bronchial epithelial cells: inhibitory effects of adiponectin. Front Pharmacol. 2020;11:56. https://doi.org/10.3389/fphar.2020.00056.

12. Kirk B, Feehan J, Lombardi G, Duque G. Muscle, bone, and fat crosstalk: the biological role of myokines, osteokines, and adipokines. Curr Osteoporos Rep. 2020. https://doi.org/10.1007/ s11914-020-00599-y.

13. Koch A, Sanson E, Voigt S, Helm A, Trautwein C, Tacke F. Serum adiponectin upon admission to the intensive care unit may predict mortality in critically ill patients. J Crit Care. 2011;26:166-74. https://doi.org/10.1016/j.jcrc.2010.07.015.

14. Carrión M, Frommer KW, Pérez-García S, Müller-Ladner U, Gomariz RP, Neumann E. The adipokine network in rheumatic joint diseases. Int J Mol Sci. 2019;20:4091. https://doi. org/10.3390/ijms20174091.

15. Bikdeli B, Madhavan MV, Jimenez D, Chuich T, Dreyfus I, Driggin E, et al. COVID-19 and thrombotic or thromboembolic disease: implications for prevention, antithrombotic therapy, and follow-up. J Am Coll Cardiol. 2020. https://doi.org/10.1016/j. jacc.2020.04.031. 